\title{
Plasmon-Based Label-Free Biosensor Using Gold Nanosphere for Dengue Detection
}

\author{
Hafiz Zeeshan Mahmood ${ }^{1}$, Asim Jilani ${ }^{2, *(\mathbb{D})}$, Sajid Farooq ${ }^{3}$, Yasir Javed ${ }^{4} \mathbb{D}$, Yasir Jamil ${ }^{4}\left(\mathbb{D}\right.$, Javed Iqbal ${ }^{2, *(\mathbb{D})}$, \\ Sami Ullah ${ }^{5}$ (D) and Swelm Wageh ${ }^{6,7}$
}

1 Department of Electrical Emgineering and Systems, Universidade Federal de Pernambuco, Recife 50670-901, Brazil; hafiz.zeeshan.mahmood@gmail.com

2 Center of Nanotechnology, King Abdulaziz University, Jeddah 21589, Saudi Arabia

3 Escola Politécnica de Pernambuco-POLI, Universidade de Pernambuco, Recife 50100-010, Brazil; samzee2315@gmail.com

4 Department of Physics, University of Agriculture, Faisalabad 38040, Pakistan; myasi60@hotmail.com (Y.J.); yasirjamil@yahoo.com (Y.J.)

5 Department of Chemistry, Faculty of Science, Research Center for Advanced Materials Science (RCAMS), King Khalid University, Abha 61413, Saudi Arabia; samichemist1@gmail.com

6 Department of Physics, Faculty of Science, King Abdulaziz University, Jeddah 21589, Saudi Arabia; wageh1@yahoo.com

7 Physics and Engineering Mathematics Department, Faculty of Electronic Engineering, Menoufia University, Menouf 32952, Egypt

* Correspondence: asim.jilane@gmail.com (A.J.); iqbaljavedch@gmail.com (J.I.)

Citation: Mahmood, H.Z.; Jilani, A.; Farooq, S.; Javed, Y.; Jamil, Y.; Iqbal, J.; Ullah, S.; Wageh, S. Plasmon-Based Label-Free Biosensor Using Gold Nanosphere for Dengue Detection. Crystals 2021, 11, 1340. https:// doi.org/10.3390/cryst11111340

Academic Editors: Daquan Yang, Fei $\mathrm{Xu}$ and Jinhui Chen

Received: 7 October 2021

Accepted: 29 October 2021

Published: 2 November 2021

Publisher's Note: MDPI stays neutral with regard to jurisdictional claims in published maps and institutional affiliations.

Copyright: (c) 2021 by the authors. Licensee MDPI, Basel, Switzerland. This article is an open access article distributed under the terms and conditions of the Creative Commons Attribution (CC BY) license (https:// creativecommons.org/licenses/by/ $4.0 /)$.
Abstract: In this study, a novel label-free immunosensor platform is developed to exploit the localized surface plasmon resonance (LSPR) phenomenon. The LSPR solution-based platform is designed by a gold nanospheres probe, functionalized with monoclonal anti-dengue antibody (IgG). Numerical calculations are performed to assess the LSPR extinction spectrum and spatial near electric field distribution around the nanoparticle surface. Important parameters that govern sensor performance, molecular and refractive index sensitivity are evaluated. On the evaluation of the platform as a molecular sensor, the detection of dengue NS1 antigens is presented. The results are consistent with the numerical simulations, which depicts the system's ability to identify dengue NS1 antigen concentrations as low as $0.07 \pm 0.01 \mu \mathrm{g} / \mathrm{mL}$, along with fosters its potential application in plasmonic sensing.

Keywords: localized surface plasmon resonance; gold nanoparticle; plasmonic sensor; dengue detection

\section{Introduction}

Optical properties of noble metallic nanoaggregates have been a rigorously studied subject, which stimulated the interest of the researchers due to their fascinating plasmonic characteristics which depend on the geometry of the nanostructure [1,2]. Due to the collective oscillations of particle's conduction electrons, the plasmonic coupling in such noble metal nanoparticles results in the huge localization of electromagnetic fields, which possess free electron gas that can strongly interact with the electromagnetic radiation to produce an interesting phenomenon known as localized surface plasmon resonance (LSPR) [2,3].

The metallic nanostructures ( $\mathrm{Au}, \mathrm{Ag}$ ) have been intensively investigated due to their unique optical properties in the field of biosensing [3], photothermal therapy [4], surface enhanced Raman scattering (SERS) [5] and various other photonic applications [6,7].

Dengue virus is an arthropod-borne virus disease transmitted by Aedes aegypti mosquitos, that has severe health risks in tropical as well as sub-tropical worldwide areas $[1,2]$. Dengue virus is primarily examined through clinical symptoms and confirmed through laboratory tests, such as immunoglobulin $\mathrm{G}(\operatorname{IgG})$, immunoglobulin $\mathrm{M}(\operatorname{IgM})$, 
enzyme linked immunosorbent assays (ELISA), point of care tests and reverse transcription polymerase chain reactions. However, the aforementioned techniques are expensive, time consuming and require a skilled person. On the contrary, the LSPR-based sensor has been explored as low-cost, fast and reliable tool for label-free detection. As the name suggests, label-free biosensing does not require labels to facilitate measurements. Instead, it exploits the intrinsic physical properties of the analytes (e.g., molecular weight, dielectric permittivity, refractive index, size, charge, electrical impedance) to detect their presence in a sample. Label-free biosensing techniques have made tremendous progress in recent years, due to their rapid and economical biomolecule detection ability in small reaction volumes. Furthermore, they lend themselves for integration into lab-on-chip platforms, and allow real time monitoring of the concentration of target analytes [8].

Various investigations based on gold nanoparticles have been conducted to design biosensors for the detection of biomolecules, such as Alzheimer [9], proteins [10] and antibodies [11,12]. Moreover, the linking of several biomolecules, such as enzymes, DNA and proteins on the surface of noble metal nanostructures approves the diversity of a plasmon-based platform for biomedical applications [13-15].

Reliability and biocompatibility of noble metal nanostructures $(\mathrm{Au}, \mathrm{Ag})$ makes them potential candidates to diagnose such infectious diseases. In particular, the gold nanoparticles (AuNPs), being a highly stabile and easy to modify surface, have become customized diagnostics probes. A pool of four dengue viruses (DENV-1, -2, -3, -4) was detected by antibody-antigen interaction using gold nanospheres through surface plasmon resonance (SPR) [16]. Although, LSPR-based optical fiber immunosensor was developed to detect NS1 antigen in serum samples for early diagnosis of dengue. However, solution-based metallic nanoparticles can present a more efficient, facile and cheap platform which exploits LSPR extinction spectrum. In contrast to SPR-based sensors, LSPR sensors have lower modeling costs, which makes them a strong candidate for bulk utilization. However, immobilization of nanostructures on a substrate and a low dynamic range are the current challenges that need to be addressed [17].

Developing a relationship between the varying refractive index in the vicinity of the particle's medium and plasmon peak shift which strongly relies on the sensing performance of LSPR-based sensor. A crucial analytical parameter to evaluate the sensing performance that has been analyzed qualitatively is termed as Bulk sensitivity: $\eta=\Delta \lambda_{\text {LSPR }} / \Delta \mathrm{n}$, which correlates to the peak shift in LSPR $\left(\Delta \lambda_{\text {LSPR }}\right)$ and is dependent on the change in refractive index $(\Delta \mathrm{n})[18]$.

In this article, we present a label-free procedure to establish a novel LSPR immunoassay platform. We investigated both the experimental and theoretical approach based on the evaluation of the spatial field distribution and field enhancement around the nanoparticles' surface, as well as the attachment of the biomolecule. Qualitative parameters which elaborate on the plasmonic sensor performance were evaluated. Molecular biosensing was demonstrated by the identification of dengue NS1 antigen.

\section{Methods and Materials}

\subsection{Numerical Analysis}

Finite element method (FEM)-based simulations were performed using RF Module in COMSOL Multiphysics (COMSOL Inc., 5.6, Burlington, MA, USA) to study the electromagnetic field interaction with gold nanosphere, as depicted in Figure 1. 


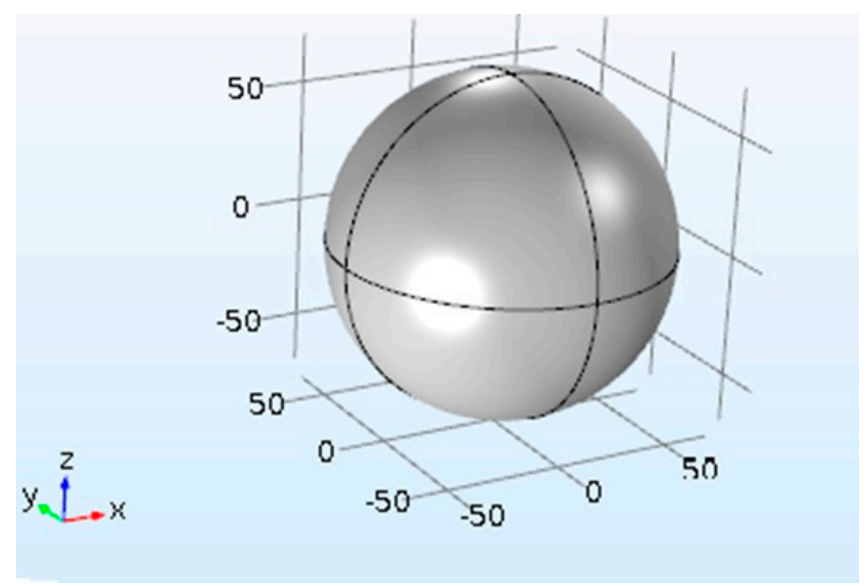

Figure 1. Gold nanosphere placed in uniform external electric field.

A perfect matching layer was introduced to avoid incident field reflections. Water was used as a surrounding medium around the AuNPs. The incident electric field was set as $1 \mathrm{~V} / \mathrm{m}$. The data for dielectric function of gold nanoparticles simulations were obtained from Johnson and Christy [14].

\subsection{Experimental Analyses}

The extinction spectrum $(400-850 \mathrm{~nm})$ were obtained using Ocean Optics spectrophotometer (HR +4000, Ocean Optics, Sāo Paulo, Brazil), while placing the samples in cuvettes (quartz), having the width of $1 \mathrm{~cm}$. Scanning electron microscopy (SEM) MIRA3 Trescan HV $20 \mathrm{kV}$ was performed after drop casting of gold nanospheres on silicon substrate. The particle size of AuNPs and their modification were obtained through SEM images.

\subsection{Preparation of Sensing Platform}

The colloidal gold nanospheres, having an average radius of $2.5 \mathrm{~nm}$ and $25 \mathrm{~nm}$, were obtained from Sigma Aldrich (St. Louis, MO, USA) and Nanocomposix (St. Louis, MO, USA), respectively. According to Vistas et al. [15], prior to modifications, the sensing platform/glass slide was hydroxylated using a Piranha solution $\left(\mathrm{H}_{2} \mathrm{SO}_{4}: \mathrm{H}_{2} \mathrm{O}_{2}\right.$, (1:3), SigmaAldrich/Merck Millipore, São Paulo, Brazil) followed by incubation in toluene prepared 2.5\% solution of mercaptopropyl-triethoxysilane (MPTS, Sigma-Aldrich/Merck Millipore São Paulo 06455-030, Brazil) for $1.5 \mathrm{~h}$. Due to silanization, the chemical bonding of the self-assembled film of MPTS with thiol group (-SH) present on the functionalized glass substrate enables the adherence of Au NPs to the surface of the substrate. Kreuzer et al. [16] reported that a prolonged incubation time prompted the dipole-dipole interaction between Au nanoaggregates, in lieu of the aforementioned finding, the functionalized surface of glass was immersed in the Au NP colloidal solution for $1 \mathrm{~h}$ to avoid the aggregation of the NPs.

The glass slice was frequently washed with deionized water obtained from Millipore Unit (United States) in order to remove the unlinked Au NPs, drying afterwards with nitrogen flow.

Afterward, the modified sensing platform with colloidal gold nanospheres was cleaned with $0.2 \mathrm{M}$ solution of nitric acid and immersed in ethanol prepared solution of $50 \mathrm{mM}$ cysteamine (2-aminoethanethiol) for two hours. On one end, the ligand thiol functional group (-SH) permitted immobilization to the metallic nanostructure surface, and the other side of the ligand/cysteamine consisting of the amine $\left(-\mathrm{NH}_{2}\right)$ group allowed attachment of the dengue antibodies with the carboxyl group.

To immobilize the anti-NS1 antibodies, an aliquot of $10 \mu \mathrm{g} / \mathrm{mL}$ of anti-dengue ( $\mathrm{pH} 7)$ was drop casted on the glass surface for an hour. For the sake of development of the 
platform, the amino groups of cysteamine were blocked by incubating with $50 \mathrm{mM}$ of glycine ( $\mathrm{pH}$ 6.5) for two hours.

Finally, to evaluate the developed sensing surface, which could identify the dengue NS1 antigen, a small volume $(4 \mu \mathrm{L})$ of antigen solution was drop casted on the sensing platform for sixty minutes. After cleaning the platform with MilliQ water, the LSPR spectrum was measured. Different concentrations of dengue NS1 antigens solution, from GenWayBio (San Diego, CA, USA), were prepared in PBS (10 Mm, pH 6.5). All major steps in assembling the immunoassay dengue sensor based on Au nanospheres are illustrated in the schematic diagram of Figure 2.

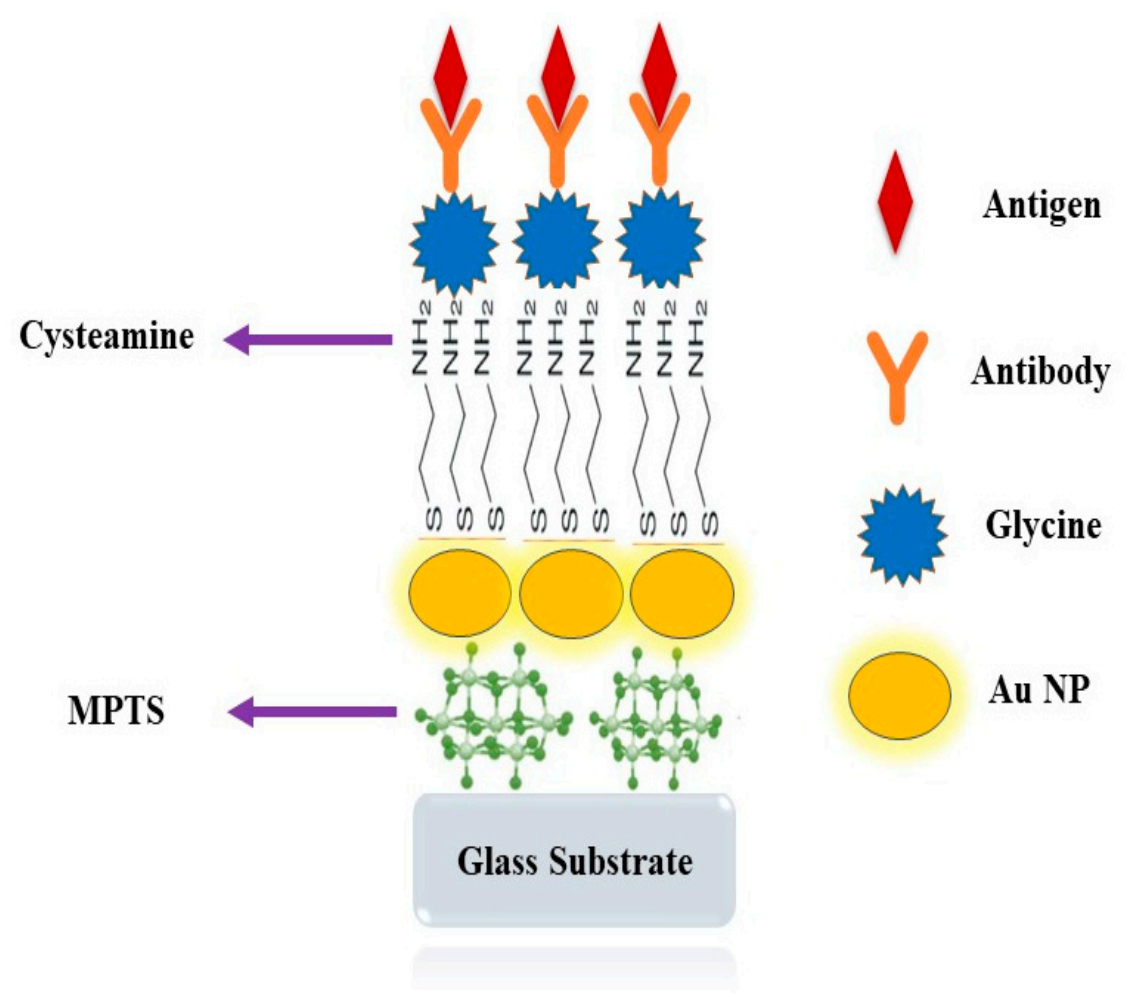

Figure 2. Schematic representation of sensing platform development.

\section{Results}

By tuning gold nanoparticles shape or size, the LSPR extinction spectra can be modulated over visible to near infra-red range. Gold nanostructures in solution phase tend to form a spherical shape, due to the smallest surface area, compare to other objects on fixing volume. Evaluation of the shape of gold nanospheres, on the basis of SEM observation, is depicted in Figure 3. 


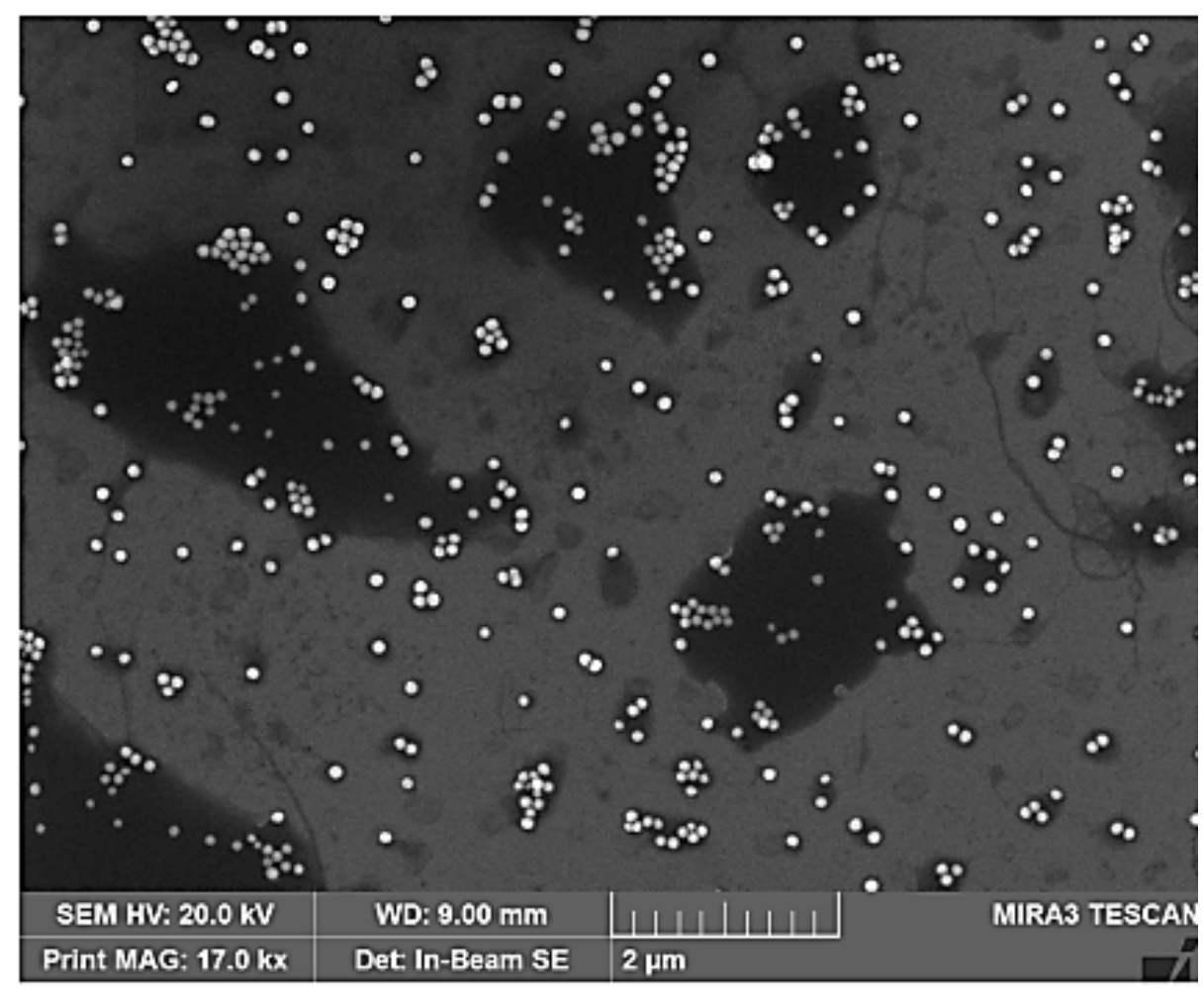

Figure 3. Scanning electron microscopy (SEM) of gold nanospheres.

Molecular LSPR-based sensing is linked with the variation in nanoparticles' extinction spectrum, as a result of adhesion of the analyte layer on the particle surface. Plasmon peak position varies with the change of the surrounding media of the nanoparticle, such as solvent $[13,17]$. Sensitivity as a function of refractive index (RI) can be described as [18]:

$$
\eta=\frac{\Delta \lambda}{\Delta \mathrm{n}}
$$

where $\Delta \mathrm{n}$ is the change in near proximity of the particle medium, and $\Delta \lambda$ is the plasmon peak shift. Figure 4 a demonstrates the theoretical elaboration of the LSPR peak position of gold nanosphere $(25 \mathrm{~nm})$ in diverse surrounding medium, such as water, ethanol, tetrahydrofuran, dimethylformamide and polyethylene glycol. As the RI of the vicinity varies (where $\mathrm{n}$ increased from 1.32 to 1.46), a clear red-shift in LSPR peak $\left(\lambda_{\text {peak }}\right)$ can be examined. RI-based sensitivity of plasmonic sensor is governed by the nanoparticle geometry. As the radius of the nanosphere increases, the AuNP surface area enhances and the surface to volume ratio changes, modifying the $\eta$ values. Figure $4 \mathrm{~b}$ shows the effects of size on the gold nanoparticle sensing efficacy. In Figure $4 \mathrm{~b}$, the radius of the particles varied from 2.5 to $25 \mathrm{~nm}$, leading to an increase in $\eta$ from 50 to $78 \mathrm{~nm} /$ RIU.

Furthermore, for small particles $(2.5-20 \mathrm{~nm})$, the absorption primarily depends on the light-nanoparticle interaction. Scattering phenomenon can be tuned by changing the nanoparticle geometry. The nonlinear behavior of the bulk sensitivity, shown in Figure $4 \mathrm{~b}$, can be empirically described as:

$$
y(r)=A+\left[\frac{\mathrm{B}}{1+\mathrm{e}^{\frac{(\mathrm{r}-\mathrm{C})}{\mathrm{D}}}}\right]
$$

where A, B, C and D are constants and $r$ represents the radius of nanospheres. 

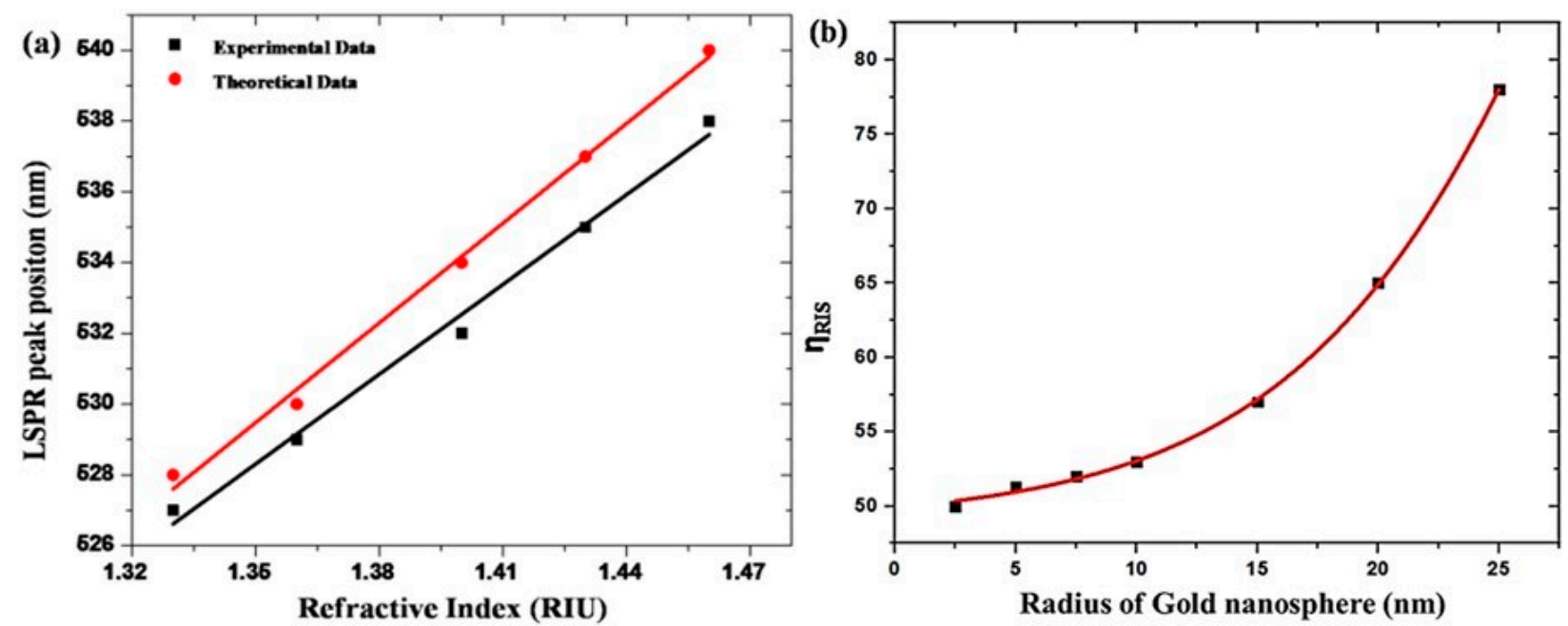

Figure 4. The LSPR peak position upon the change in refractive index of the surrounding solvents for gold nanospheres of radius $25 \mathrm{~nm}(\mathbf{a})$, and refractive index sensitivity as a function of radius for spherical NPs (b).

Regardless of the limitation of the quasi-static approach on small nanostructure, the calculated and the measured values of LSPR peak wavelength and bulk sensitivity are in good agreement, as shown in Table 1 . The difference of $14 \%$ and $9 \%$ in the experimental and theoretical values of bulk sensitivity $(\eta)$ were observed for nanostructure radii of $2.5 \mathrm{~nm}$ and $25 \mathrm{~nm}$, respectively.

Table 1. The LSPR peak wavelength and bulk sensitivity values of gold spherical NPs of different size.

\begin{tabular}{ccccccc}
\hline & Size of NPs & & \multicolumn{2}{c}{ Experimental Data } & \multicolumn{2}{c}{ Theoretical Data } \\
\hline Radius $(\mathrm{nm})$ & $\lambda_{\text {LSPR }}(\mathrm{nm})$ & $\eta_{\text {RIS }}(\mathrm{nm} / \mathrm{RIU})$ & $\lambda_{\text {LSPR }}(\mathrm{nm})$ & $\eta_{\text {RIS }}(\mathrm{nm} / \mathrm{RIU})$ & $\lambda_{\text {LSPR }}$ Error & $\eta_{\text {RIS }}$ Error \\
\hline 2.5 & 519 & 58 & 518 & 50 & $0.2 \%$ & $14 \%$ \\
\hline 25 & 527 & 86 & 528 & 78 & $0.2 \%$ & $9 \%$ \\
\hline
\end{tabular}

The field decay length $\left(l_{d}\right)$ is a vital parameter in plasmon-based molecular sensing. The values of $l_{d}$ depend on size, shape and material composition of the nanostructure [19]. Figure 5 a shows the EM field distribution around an individual gold nanosphere $(r=25 \mathrm{~nm})$ embedded in water. The $l_{d}$ of the single NP may be fitted by Prony's method by evaluating the sum of exponentials [20]. Moreover, Barbillon et al. procured a behavior description of the EM field decay, by using a single exponential fitting curve [21]. The inset of Figure 5a depicts a 2D evaluation of the EM field distribution near the gold nanosphere surface.

Figure $5 \mathrm{~b}$ demonstrates the tendency of the EM field decay length to the radii of different size nanospheres. It is apparent that while increasing the radii of the NPs, EM field decay length grows. The calculated data are well fitted through the linear plot with slope $\sim 0.19$, and $\mathrm{R}^{2}=0.997$. For surface plasmon resonance (SPR) sensors, the $l_{d}$ values are of the order of $200 \mathrm{~nm}$ to $300 \mathrm{~nm}$, while for LSPR sensors they are within few nanometers' regime. 

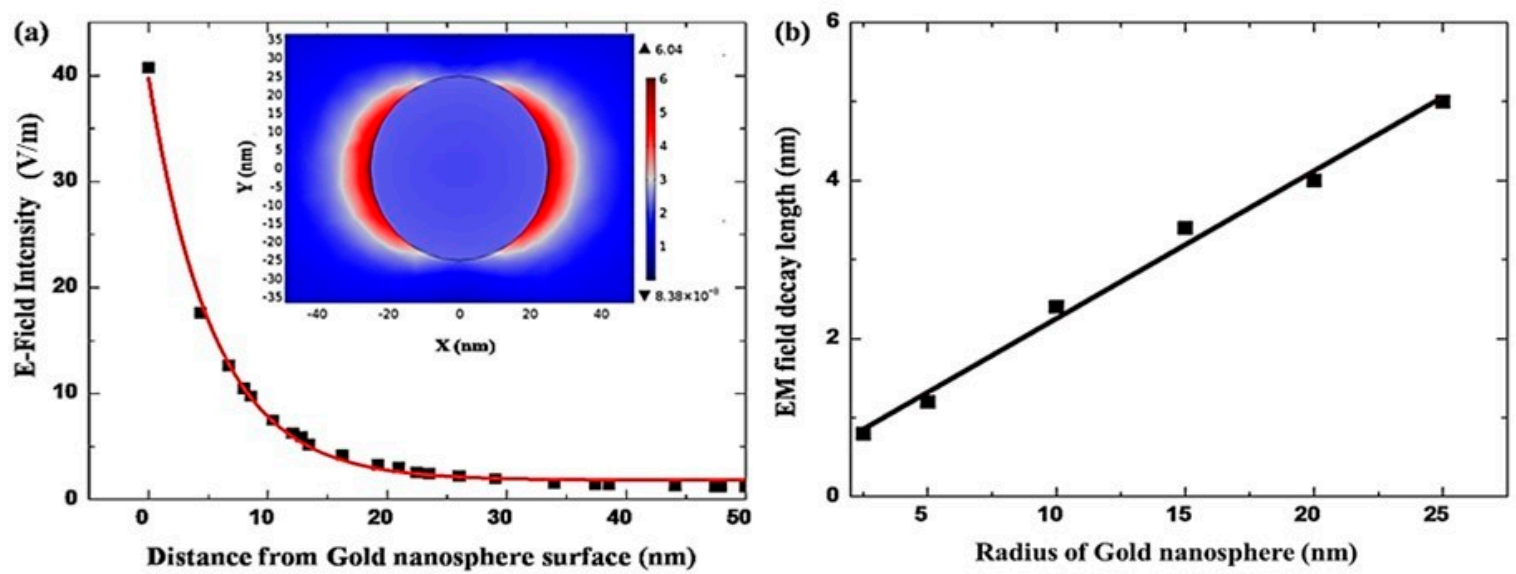

Figure 5. The E-field intensity of gold nanosphere $(\mathrm{r}=25 \mathrm{~nm}$ ) using FEM in homogenous medium (inset shows the field distribution $\left(\left|\mathrm{E} / \mathrm{E}_{0}\right|\right)$ around the gold nanosphere) $\mathrm{n}=1.33(\mathbf{a})$, and relation between NPs radii versus $l_{d}(\mathbf{b})$.

In Figure 6, a single dielectric shell with refractive index 1.47 having a shell thickness from $0.5 \mathrm{~nm}$ to $10 \mathrm{~nm}$ was assumed. By increasing adsorbate shell thickness, the LSPR peak varies linearly for Au nanosphere $(25 \mathrm{~nm})$. On the contrary, with Au nanosphere with $2.5 \mathrm{~nm}$ radius, the peak shift is not significant while increasing (more than $2 \mathrm{~nm}$ ) the thickness of the dielectric shell. For small particles, LSPR peak is determined by the absorption process, field decay length is limited to few $\mathrm{nm}$ and $\eta$ values are around $50 \mathrm{~nm} / \mathrm{RIU}$ (for $\mathrm{r}=2.5 \mathrm{~nm}$ ), and low values for $\Delta \lambda$ were observed, about $5.6 \mathrm{~nm}$ to $7 \mathrm{~nm}$ shift. Particles with a radius greater than $20 \mathrm{~nm}$ enhanced the RI values considerably (as demonstrated earlier in Figure 4b), therefore an increase in the LSPR peak shift can be observed in Figure 6.

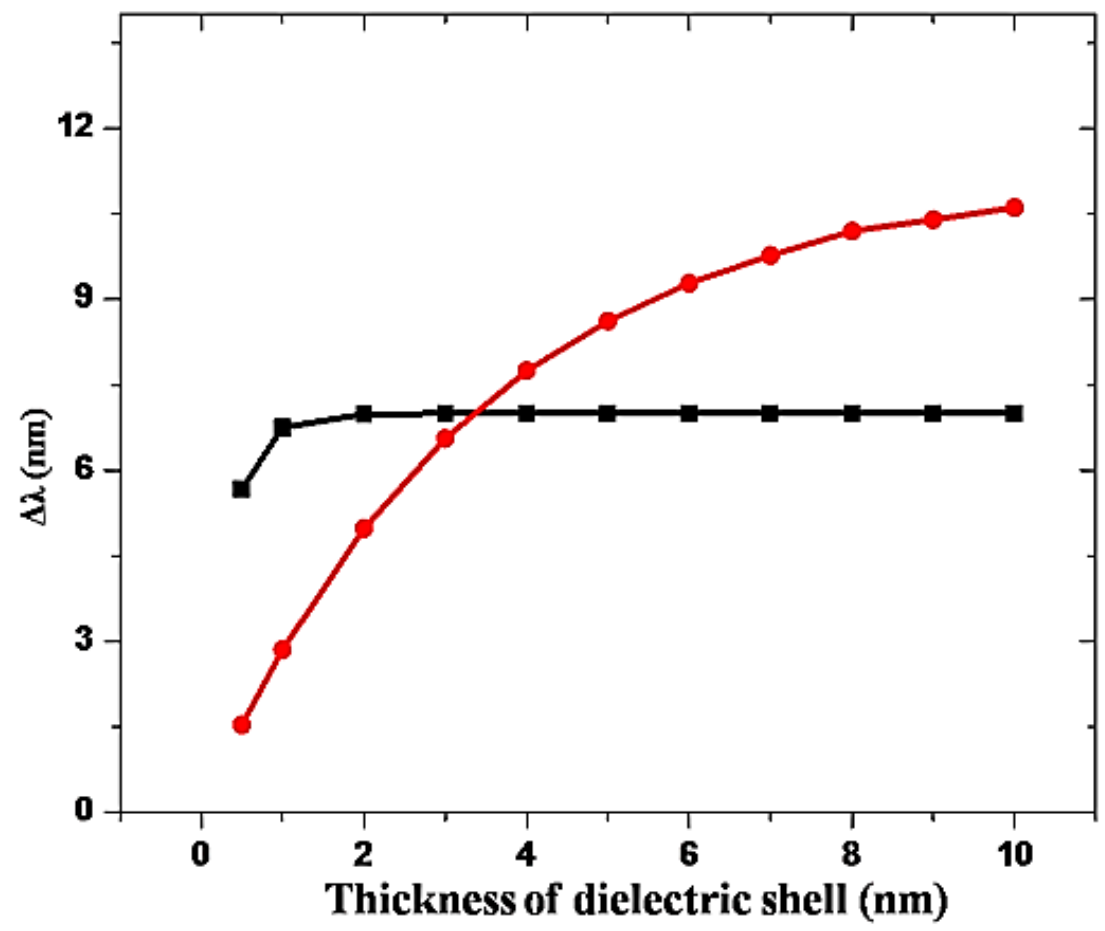

Figure 6. LSPR spectral shift of gold nanospheres of radii $2.5 \mathrm{~nm}$ (black square) and $25 \mathrm{~nm}$ (red circle) with dielectric shells of varying thickness. 
This is interpreted as around $25 \mathrm{~nm}$ radius of AuNP exhibits a high field distribution corresponding to an approximately optimum plasmon peak shift, as depicted in Figure 7. On the basis of this observation, we used $25 \mathrm{~nm}$ radius Au particles for the detection of dengue NS1 antigen. The formation of amide bond occurs with carboxyl group of anti-NS1 antibody and amine group of cysteamine. Moreover, glycine aqueous solution was used to promote strong bonds between the IgG and the amine group of cysteamine. Non-specific bindings were blocked by incubating the sensing platform in a solution of $50 \mathrm{~m} \mathrm{~mol} \mathrm{~L}^{-1}$ glycine, prepared in PBS ( $\left.\mathrm{pH} 6.5,10 \mathrm{mmol} \mathrm{L}^{-1}\right)$ for two hours.

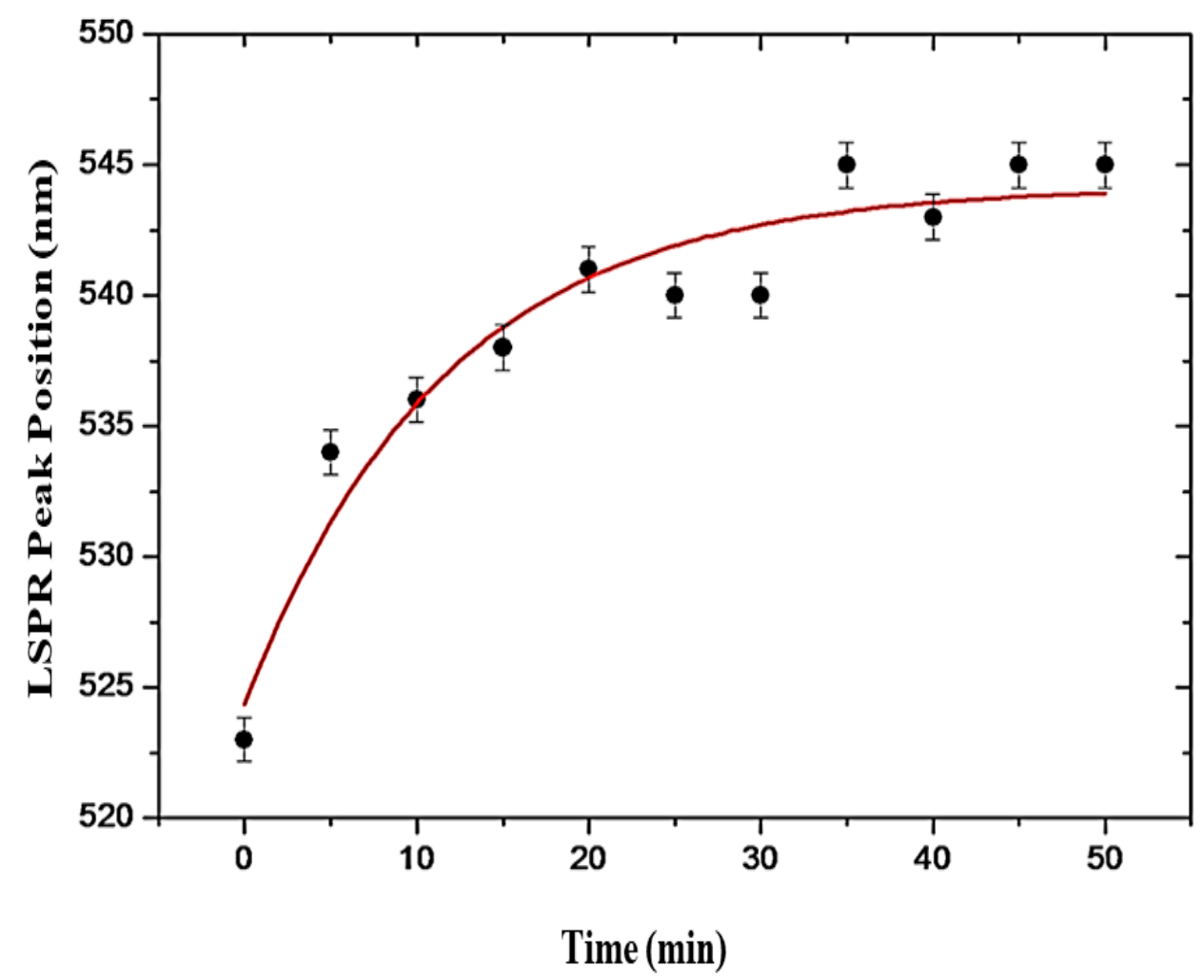

Figure 7. The LSPR spectral shift of AuNPs for $25 \mathrm{~nm}$ on the adsorption of cysteamine with increasing time.

Figure 8 shows the LSPR extinction spectrum of the AuNPs platform, starting with a spectral peak at $526 \mathrm{~nm}$. The adsorption of cysteamine on the AuNPs surface depicts an LSPR peak shift (red curve) around $530 \mathrm{~nm}$. The immobilization of IgG $(1.0 \mu \mathrm{g} / \mathrm{mL})$ on the NP platform is represented by the green curve. After the isolation of unbound cysteamine functional group (ligand) and immobilization of anti-NS1 antibody, the plasmonic sensor is ready to detect dengue NS1 antigen. When dengue NS1 antigen was identified by the platform (blue curve), another significant spectrum shift was observed. The clear peak shift can be seen $\sim 12 \mathrm{~nm}$ (red curve), after the binding of amide bond with anti-NS1 antibody as depicted in Figure 8. The extinction spectrum clearly shows a red-shift with low concentration $0.07 \pm 0.01 \mu \mathrm{g} / \mathrm{mL}$, as represented by the green curve. 


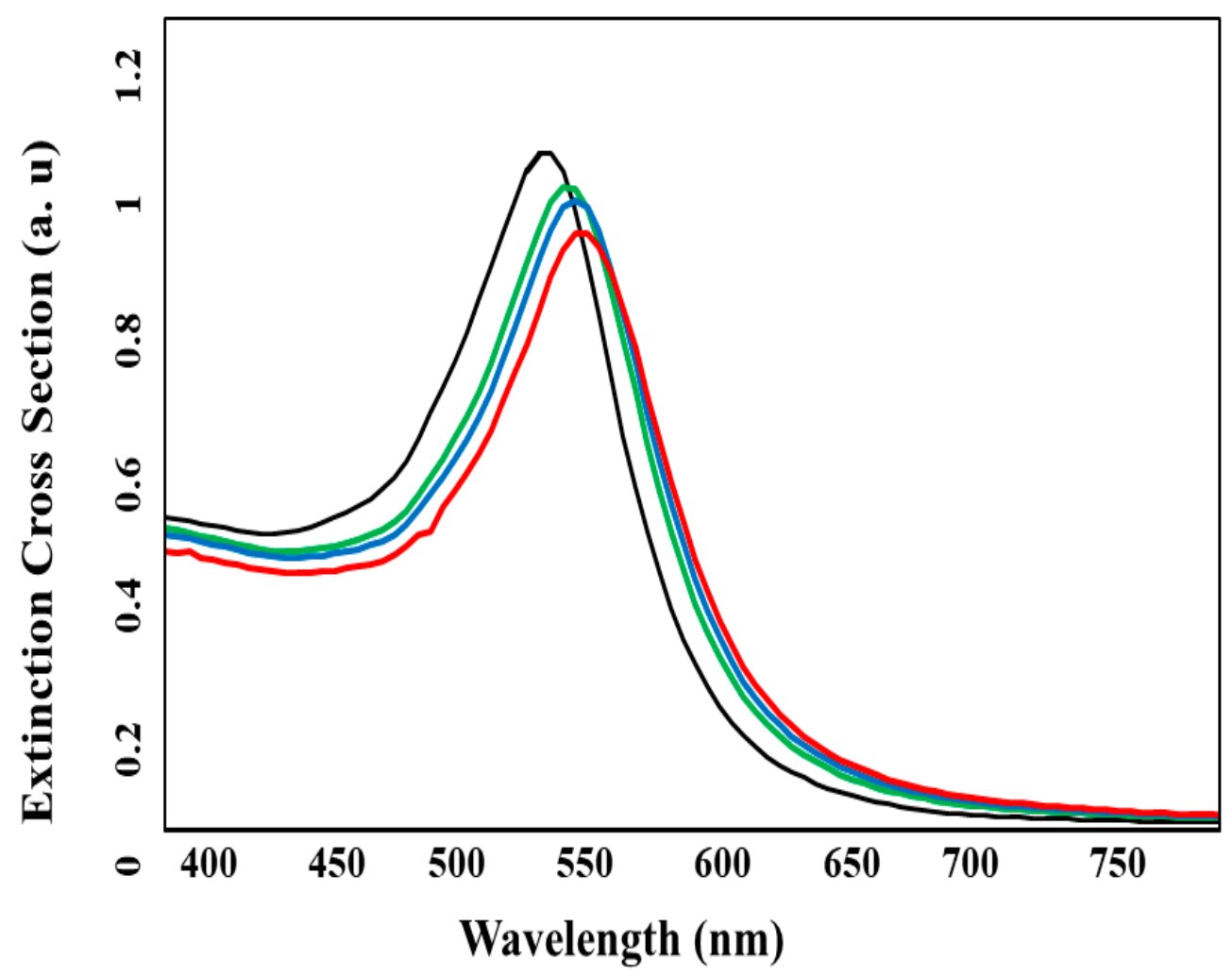

Figure 8. The label-free biosensing of anti-NS1 antibody to NS1 antigen using colloidal Au nanosphere suspension. (Black Curve-AuNP, Green Curve-Au-Cysteamine, Blue Curve-AuCysteamine-Antibodies, Red Curve-Antigen Detection).

\section{Discussion}

The LSPR peak shift served as a measure of the respective sensitivity. The measurements were supported by SEM images in order to confirm the geometry of the nanostructure under probe. When it comes to the comparison of detection limit and sensitivity of nanoaggregates reported in the literature with those of the roughly spherical $\mathrm{Au} / \mathrm{Ag}$ core-shell NPs, the spherical structures showed comparable or even higher sensitivities than the complex geometries [22], as depicted in Table 2. The theoretical calculation based on Finite element method was supported by the experimental finding of optical properties of such core-shell NPs. Theoretical results reveal that for shells with a higher refractive index and longer thickness, the use of $\sim 25 \mathrm{~nm}$ radius NPs would lead to LSPR-based sensors with high sensitivity.

Regardless of the limitation of the quasi-static approach, LSPR peak wavelength and bulk sensitivity are in good agreement, with $0.2 \%$ difference $\left(\lambda_{\text {LSPR }}\right.$-error) being observed between the calculated and experimental spectral peak shift values. Due to the electrostatic interactions between negatively charged citrate on Au NPs surfaces and positively charged proteins groups, the conjugation of proteins on colloidal Au nanostructures can be achieved [23]. In lieu of this, extinction spectra of spherical Au NPs were calculated, and the presence of dengue NS1 antigen with increased sensitivity was confirmed. One possible explanation of this effect is the overlapping of two plasmon bands within the nanoparticle, which changes their relative intensity upon the change of surrounding medium/refractive index. Moreover, the choice of the nanostructure with best performances is therefore dependent on the refractive index and effective thickness of the adsorbate molecules [24,25], which might be measured by the use of two medium or two-color approaches in classical SPR spectroscopy [26-28]. 
Table 2. Comparison of SPR- and LSPR-based biosensors for biological molecules detection.

\begin{tabular}{|c|c|c|c|c|c|}
\hline Nanostructure & Biological Molecule & $\begin{array}{l}\text { Optical } \\
\text { Sensor }\end{array}$ & $\begin{array}{c}\text { Detection } \\
\text { Limit }\end{array}$ & $\begin{array}{c}\text { Sensitivity } \\
\text { nm/RIU }\end{array}$ & References \\
\hline Single Au NP & Streptavidin & SPR & $50 \mu \mathrm{M}$ & - & [29] \\
\hline Au NPs & Streptavidin & SPR & $0.05 \mu \mathrm{M}$ & 362 & [30] \\
\hline Au NPs & Dengue E-protein & SPR & $0.01 \mathrm{nM}$ & $39.96(\% / \mathrm{nM})$ & [31] \\
\hline Cd Quantum dots & Dengue E-protein & SPR & $1 \mathrm{pM}$ & $5.49\left({ }^{\circ} / \mathrm{nM}\right)$ & [32] \\
\hline Graphene Oxide & Dengue E-protein & SPR & $0.5 \mathrm{pM}$ & - & [33] \\
\hline $\begin{array}{l}\text { Reduced Graphene } \\
\text { Oxide }\end{array}$ & Dengue 2E-protein & SPR & $0.08 \mathrm{pM}$ & $0.25\left({ }^{\circ} / \mathrm{pM}\right)$ & {$[34]$} \\
\hline Ag NPs & Candida Albicans & LSPR & * $30 \mu \mathrm{M}$ & 290 & [35] \\
\hline $\mathrm{Au}$ NPs & Gliadin & LSPR & - & 364 & [36] \\
\hline $\mathrm{Au}$ NPs & Dengue NS1 & LSPR & $* 1.2 \mu \mathrm{M}$ & 435 & This work \\
\hline
\end{tabular}

* Some values have been recalculated to provide better comparisons in terms of $\mathrm{mL}$.

Omar et al. monitored an SPR sensor by immobilization of IgM on a gold surface for the detection of DENV. By modification of the active layer, sensitivity and selectivity were improved for the early detection of DENV [31]. Dutra and colleague presented an SPR-based immunosensor for human cardiac troponin $\mathrm{T}$ using specific binding at carboxymethyldextran-modified gold chip, which showed good repeatability with $3.4 \%$ in a solution of $1 \%$ SDS [37]. In another study, Dutra et al. explored a surface plasmon resonance immunosensor exhibiting a linear response range for cTnT between 0.05 and $4.5 \mathrm{ng} / \mathrm{mL}(\mathrm{r}=0.997, p<<0.01)$ with good reproducibility $(\mathrm{CV}=4.4 \%)$ [38].

Our main focus in this study was to analytically study the optical properties of gold nanoparticles on an optically transparent substrate as a function of size, as the size of nanostructures strongly influences the sensitivity of the plasmonic sensor [35]. With the precise goal of optimization of LSPR-based biosensor design, Finite element method was utilized, which leads to the assessment of the near field distribution around the nanoparticle surface as well as the LSPR spectrum. The sensing platform was able to identify a small concentration $(0.07 \pm 0.01 \mu \mathrm{g} / \mathrm{mL})$ of dengue NS1 antigen in a solution dropped on the platform. Farooq et al. have taken the similar approach to fabricate a plasmonic biosensor using silver nanospheres, with the important difference that the silver nanostructures showed less molecular sensitivity as a function of the nanoparticle size [35]. These results show a possibility of improving an LSPR-based sensor by adding an extra layer (metallic) of certain thickness.

\section{Conclusions}

The LSPR solution-based platform was designed by gold nanospheres, functionalized with monoclonal anti-dengue antibody (IgG), as well as numerical calculations were performed to assess the LSPR extinction spectrum and electric field distribution around the nanoparticle surface. After evaluation of the under-probe platform, the identification of dengue NS1 antigens was confirmed. This illustrates that our proposed labelfree platform has the ability to identify dengue NS1 antigen at concentrations as low as $0.07 \pm 0.01 \mu \mathrm{g} / \mathrm{mL}$, indicating the possibility of this platform as an immunosensor.

Author Contributions: For research articles with several authors, Conceptualization, H.Z.M. and A.J.; Data curation, S.F. and S.U.; Formal analysis, S.F., Y.J. (Yasir Javed), Y.J. (Yasir Jamil) and J.I.; Funding acquisition, S.U.; Investigation, H.Z.M. and S.W.; Methodology, A.J. and S.W.; Project administration, A.J., Y.J. (Yasir Jamil) and J.I.; Software, S.F. and Y.J. (Yasir Jamil); Supervision, A.J. and J.I.; Validation, Y.J. (Yasir Jamil); Visualization, Y.J. (Yasir Jamil); Writing-review \& editing, A.J., S.U. and S.W. All authors have read and agreed to the published version of the manuscript.

Funding: Authors acknowledge support and funding of King Khalid University; grant no: $\mathrm{KKU} / \mathrm{RCAMS} / 008 / 21$.

Acknowledgments: Authors acknowledge support and funding of King Khalid University; grant no: KKU/RCAMS/008/21. Yasir Jamil is thankful to HEC (Pakistan) for financial support under NRPU 6409. 
Conflicts of Interest: The authors declare that there is no conflict of interest.

\section{References}

1. Haes, A.J.; Hall, W.P.; Chang, L.; Klein, W.L.; Van Duyne, R.P. A Localized Surface Plasmon Resonance Biosensor: First Steps toward an Assay for Alzheimer's Disease. Nano Lett. 2004, 4, 1029-1034. [CrossRef]

2. Singhana, B.; Slattery, P.; Chen, A.; Wallace, M.; Melancon, M.P. Light-Activatable Gold Nanoshells for Drug Delivery Applications. AAPS PharmSciTech 2014, 15, 741-752. [CrossRef]

3. Cinel, N.A.; Bütün, S.; Özbay, E. Electron beam lithography designed silver nanodisks used as label free nano-biosensors based on localized surface plasmon resonance. Opt. Express 2012, 20, 2587-2597. [CrossRef]

4. Konan, Y.N.; Gurny, R.; Allémann, E. State of the art in the delivery of photosensibilizers for photodynamic therapy. J. Photochem. Photobiol. B Biol. 2002, 66, 89-106. [CrossRef]

5. Lakowicz, J.R. Radiative decay engineering 5: Metal-enhanced fluorescence and plasmon emission. Anal. Biochem. 2005, 337, 171-194. [CrossRef]

6. Ross, M.B.; Schatz, G.C. Radiative effects in plasmonic aluminum and silver nanospheres and nanorods. J. Phys. D Appl. Phys. 2014, 48, 184004. [CrossRef]

7. Aslan, K.; Gryczynski, I.; Malicka, J.; Matveeva, E.; Lakowicz, J.R.; Geddes, C.D. Metal-enhanced fluorescence: An emerging tool in biotechnology. Curr. Opin. Biotechnol. 2005, 16, 55-62. [CrossRef] [PubMed]

8. Jain, P.; Huang, X.; El-Sayed, I.H.; El-Sayed, M.A. Noble Metals on the Nanoscale: Optical and Photothermal Properties and Some Applications in Imaging, Sensing, Biology, and Medicine. Accounts Chem. Res. 2008, 41, 1578-1586. [CrossRef]

9. Khan, A.U.; Khan, S.; Azam, A.; Alam, F. Gold nanoparticles enhance methylene blue-induced photodynamic therapy: A novel therapeutic approach to inhibit Candida albicans biofilm. Int. J. Nanomed. 2012, 7, 3245-3257. [CrossRef] [PubMed]

10. Soler, M.; Estevez, M.-C.; Villar-Vazquez, R.; Casal, J.I.; Lechuga, L.M. Label-free nanoplasmonic sensing of tumor-associate autoantibodies for early diagnosis of colorectal cancer. Anal. Chim. Acta 2016, 930, 31-38. [CrossRef]

11. Fonsaca, J.E.; Moreira, M.P.; Farooq, S.; de Araujo, R.E.; de Matos, C.J.; Grasseschi, D. Surface Plasmon Resonance Platforms for Chemical and Bio Sensing. In Reference Module in Biomedical Sciences; Elsevier: Amsterdam, The Netherlands, 2021; ISBN 9780128012383. [CrossRef]

12. Fales, A.M.; Yuan, H.; Vo-Dinh, T. Silica-Coated Gold Nanostars for Combined Surface-Enhanced Raman Scattering (SERS) Detection and Singlet-Oxygen Generation: A Potential Nanoplatform for Theranostics. Langmuir 2011, 27, 12186-12190. [CrossRef] [PubMed]

13. Park, T.J.; Lee, S.J.; Kim, D.-K.; Heo, N.S.; Park, J.Y.; Lee, S.Y. Development of label-free optical diagnosis for sensitive detection of influenza virus with genetically engineered fusion protein. Talanta 2012, 89, 246-252. [CrossRef] [PubMed]

14. Johnson, P.B.; Christy, R.W. Optical Constants of the Noble Metals. Phys. Rev. B 1972, 6, 4370-4379. [CrossRef]

15. Vistas, C.R.; Águas, A.C.; Ferreira, G.N. Silanization of glass chips-A factorial approach for optimization. Appl. Surf. Sci. 2013, 286, 314-318. [CrossRef]

16. Kreuzer, M.P.; Quidant, R.; Salvador, J.-P.; Marco, M.-P.; Badenes, G. Colloidal-based localized surface plasmon resonance (LSPR) biosensor for the quantitative determination of stanozolol. Anal. Bioanal. Chem. 2008, 391, 1813-1820. [CrossRef]

17. Kelly, K.L.; Coronado, E.; Zhao, L.L.; Schatz, G.C. The Optical Properties of Metal Nanoparticles: The Influence of Size, Shape, and Dielectric Environment. J. Phys. Chem. B 2002, 107, 668-677. [CrossRef]

18. Farooq, S.; Mahmood, H.Z.; Rativa, D.; Bouchonneau, N.; Lins, E.; Fontana, J.; de Araujo, R.E. Optimizing gold nanorods dimer structure for sensing platform. In Proceedings of the 2018 SBFoton International Optics and Photonics Conference (SBFoton IOPC), Campinas, Brazil, 8-10 October 2018.

19. Farooq, S.; Nunes, F.D.; de Araujo, R.E. Optical properties of silver nanoplates and perspectives for biomedical applications Photon-Nanostruct.-Fundam. Appl. 2018, 31, 160-167. [CrossRef]

20. Bukasov, R.; Shumaker-Parry, J.S. Highly Tunable Infrared Extinction Properties of Gold Nanocrescents. Nano Lett. 2007, 7, 1113-1118. [CrossRef]

21. Barbillon, G. Determination of evanescent electric field decay length of metallic nanodisks by using localized surface plasmon spectroscopy. J. Mater. Sci. Eng. 2010, 4, 1934-8959.

22. Steinbrück, A.; Stranik, O.; Csaki, A.; Fritzsche, W. Sensoric potential of gold-silver core-shell nanoparticles. Anal. Bioanal. Chem. 2011, 401, 1241-1249. [CrossRef] [PubMed]

23. Zharov, V.P.; Galitovsky, V.; Viegas, M. Photothermal detection of local thermal effects during selective nanophotothermolysis. Appl. Phys. Lett. 2003, 83, 4897-4899. [CrossRef]

24. Singh, S.; Numan, A.; Zhan, Y.; Singh, V.; Alam, A.; Van Hung, T.; Nam, N.D. Low-potential immunosensor-based detection of the vascular growth factor 165 (VEGF165) using the nanocomposite platform of cobalt metal-organic framework. RSC Adv. 2020, 10, 27288-27296. [CrossRef]

25. Numan, A.; Shahid, M.M.; Omar, F.S.; Ramesh, K.; Ramesh, S. Facile fabrication of cobalt oxide nanograin-decorated reduced graphene oxide composite as ultrasensitive platform for dopamine detection. Sens. Actuators B Chem. 2017, 238, 1043-1051. [CrossRef]

26. Singh, S.; Numan, A.; Sharma, D.; Shukla, R.; Alexander, A.; Jain, G.K.; Ahmad, F.J.; Kesharwani, P. Epidemiology, virology and clinical aspects of hantavirus infections: An overview. Int. J. Environ. Health Res. 2021, 22, 1-13. [CrossRef] 
27. Numan, A.; Shahid, M.M.; Omar, F.S.; Rafique, S.; Bashir, S.; Ramesh, K.; Ramesh, S. Binary nanocomposite based on $\mathrm{Co}_{3} \mathrm{O}_{4}$ nanocubes and multiwalled carbon nanotubes as an ultrasensitive platform for amperometric determination of dopamine. Microchim. Acta 2017, 184, 2739-2748. [CrossRef]

28. Underwood, S.; Mulvaney, P. Effect of the Solution Refractive Index on the Color of Gold Colloids. Langmuir 1994, 10, 3427-3430. [CrossRef]

29. Raschke, G.; Kowarik, S.; Franzl, T.; Sönnichsen, C.; Klar, T.A.; Feldmann, J.; Nichtl, A.; Kürzinger, K. Biomolecular Recognition Based on Single Gold Nanoparticle Light Scattering. Nano Lett. 2003, 3, 935-938. [CrossRef]

30. Nath, N.; Chilkoti, A. Label-Free Biosensing by Surface Plasmon Resonance of Nanoparticles on Glass: Optimization of Nanoparticle Size. Anal. Chem. 2004, 76, 5370-5378. [CrossRef]

31. Omar, N.A.S.; Fen, Y.W.; Abdullah, J.; Chik, C.E.N.C.E.; Mahdi, M.A. Development of an optical sensor based on surface plasmon resonance phenomenon for diagnosis of dengue virus E-protein. Sens. Bio-Sens. Res. 2018, 20, 16-21. [CrossRef]

32. Omar, N.A.S.; Fen, Y.W.; Abdullah, J.; Zaid, M.H.M.; Daniyal, W.M.E.M.M.; Mahdi, M.A. Sensitive surface plasmon resonance performance of cadmium sulfide quantum dots-amine functionalized graphene oxide based thin film towards dengue virus E-protein. Opt. Laser Technol. 2019, 114, 204-208. [CrossRef]

33. Omar, N.A.S.; Fen, Y.W.; Abdullah, J.; Sadrolhosseini, A.R.; Kamil, Y.M.; Fauzi, N.; Illya, M.; Hashim, H.S.; Mahdi, M.A. Quantitative and Selective Surface Plasmon Resonance Response Based on a Reduced Graphene Oxide-Polyamidoamine Nanocomposite for Detection of Dengue Virus E-Proteins. Nanomaterials 2020, 10, 569. [CrossRef] [PubMed]

34. Omar, N.A.S.; Fen, Y.W.; Abdullah, J.; Kamil, Y.M.; Daniyal, W.M.E.M.M.; Sadrolhosseini, A.R.; Mahdi, M.A. Sensitive Detection of Dengue Virus Type 2 E-Proteins Signals Using Self-Assembled Monolayers/Reduced Graphene Oxide-PAMAM Dendrimer Thin Film-SPR Optical Sensor. Sci. Rep. 2020, 10, 2374. [CrossRef] [PubMed]

35. Farooq, S.; Neves, W.W.; Pandoli, O.; Del Rosso, T.; de Lima, L.M.; Dutra, R.F.; de Araujo, R.E. Engineering a plasmonic sensing platform for Candida albicans antigen Identification. J. Nanophotonics 2018, 12, 3. [CrossRef]

36. Mahmood, H.Z.; Farooq, S.; Lins, E.C. Optimizing the Plasmonic Sensing of Silica Coated Au/Ag Nanoshells. Int. J. Sci. Eng. Investig. (IJSEI) 2019, 8, 140-145.

37. Dutra, R.F.; Kubota, L.T. An SPR immunosensor for human cardiac troponin T using specific binding avidin to biotin at carboxymethyldextran-modified gold chip. Clin. Chim. Acta 2007, 376, 114-120. [CrossRef]

38. Dutra, R.F.; Mendes, R.K.; da Silva, V.L.; Kubota, L.T. Surface plasmon resonance immunosensor for human cardiac troponin T based on self-assembled monolayer. J. Pharm. Biomed. Anal. 2007, 43, 1744-1750. [CrossRef] [PubMed] 